\section{Do we need the PFAPA syndrome in adults with non-monogenic periodic fevers?}

We read with great interest the article by Gattorno et al proposing a new set of criteria for the classification of autoinflammatory recurrent fevers. ${ }^{1}$ This year's Paediatric Rheumatology INternational Trials Organisation(PRINTO) criteria are the third set of criteria for periodic fever, aphthous stomatitis, pharyngitis and cervical adenitis (PFAPA) syndrome in 3 years. ${ }^{1-3}$ While these three different sets share common points, they also include distinct clinical features, thus resulting in discrepancies in the classification of patients.

To illustrate this issue, we report the clinical characteristics of a cohort of 34 consecutive adult patients (see table 1) followed in our centre between 2010 and 2018, and diagnosed with PFAPA based on the modified Marshall's criteria ${ }^{4}$ (available as online supplementary material) with the exclusion of age at onset. Within this cohort, we sorted patients according to whether they did or did not meet one of the three sets of classification criteria (ie, Cantarini 2017, Vanoni 2018 and the PRINTO 2019 criteria available as online supplementary material). For Vanoni's criteria, we did not apply the age criterion. Regarding treatment response, we defined partial response as a clinically significant decrease in either the duration, the frequency or the intensity of flares as assessed by the treating physician. Complete response was defined as absence of flare. Of our 34 patients, 6 met Cantarini's criteria (designed specifically for adult-onset PFAPA), 17 met Vanoni's criteria, 13 met the PRINTO 2019 criteria and 13 did not meet any of the recent classification criteria for PFAPA (see online supplementary figure 1). Thirty-two (94\%) patients had undergone genetic testing based on their specific characteristics, which all yielded inconclusive results. Regardless of the set of criteria fulfilled, our patients displayed globally similar therapeutic response and disease course. None developed AA amyloidosis. Most patients managed their flares using short courses of oral corticosteroids. Furthermore, long-term treatment with colchicine was successful in approximately $50 \%$ of patients (partial or complete response rate ranging from $43 \%$ to $76 \%)$. During follow-up, spontaneous remission or decrease in the duration, frequency or intensity of flares occurred in $50 \%$ of

Table 1 Patients' characteristics and therapeutic response according to the set of criteria fulfilled

\begin{tabular}{|c|c|c|c|c|c|}
\hline & Overall $(n=34)$ & Cantarini's criteria $(n=6)$ & Vanoni's criteria $(n=17)$ & $\begin{array}{l}\text { PRINTO } 2019 \text { criteria } \\
(n=13)\end{array}$ & $\begin{array}{l}\text { Not classified* } \\
(n=13)\end{array}$ \\
\hline Female/male & $23 / 11$ & $4 / 2$ & $12 / 5$ & $8 / 5$ & $9 / 4$ \\
\hline Age at onset (years) & $5.0(2.4-15.8)$ & $21.5(15.8-25.3)$ & $5.0(1.5-9.0)$ & $2.5(0.65-5.0)$ & $7.0(4.5-16.0)$ \\
\hline $\begin{array}{l}\text { Annual frequency of flares } \\
\text { before start of therapy }\end{array}$ & $12.0(6.5-12.0)$ & $10.0(5.8-12.0)$ & $12.0(10.0-12.0)$ & $12.0(9.3-14.8)$ & $8.3(3.3-12.0)$ \\
\hline $\begin{array}{l}\text { Length of flares before start } \\
\text { of therapy (days) }\end{array}$ & $3.8(3.0-4.6)$ & $4.0(3.9-4.8)$ & $4.0(3.3-4.6)$ & $4.3(3.3-5.1)$ & $3.0(2.6-3.5)$ \\
\hline CRP during flares (mg/L) & $113(53-150)$ & $152(59-201)$ & $104(57-140)$ & $111(60-144)$ & $67(38-128)$ \\
\hline \multicolumn{6}{|l|}{ Acute treatment of flares } \\
\hline NSAID (n) & 7 & 0 & 5 & 4 & 1 \\
\hline Corticosteroids (n) & 24 & 5 & 13 & 11 & 8 \\
\hline Anakinra (n) & 5 & 3 & 3 & 2 & 1 \\
\hline \multicolumn{6}{|l|}{ Long-term treatment } \\
\hline NR $(\%)$ & 29 & 50 & 27 & 43 & 13 \\
\hline $\mathrm{AE}(\%)$ & 19 & 0 & 27 & 14 & 13 \\
\hline Anakinra (n) & 1 & 0 & 1 & 0 & 0 \\
\hline CR (\%) & 100 & - & 100 & - & - \\
\hline PR (\%) & 0 & - & 0 & - & - \\
\hline NR (\%) & 0 & - & 0 & - & - \\
\hline Canakinumab (n) & 1 & 1 & 0 & 0 & 0 \\
\hline CR (\%) & 0 & 0 & - & - & - \\
\hline PR (\%) & 0 & 0 & - & - & - \\
\hline NR (\%) & 100 & 100 & - & - & - \\
\hline $\begin{array}{l}\text { Tonsillectomy/ } \\
\text { adenoidectomy (n) }\end{array}$ & 11 & 1 & 6 & 4 & 4 \\
\hline
\end{tabular}

Continuous variables are given in median (IQR).

*Patients fulfilling only modified Marshall's criteria.

$A E$, adverse effect leading to discontinuation; CR, complete response;CRP, C-reactive protein; NR, no response; NSAID, nonsteroidal anti-inflammatory drug;PFAPA, periodic fever, aphthous stomatitis, pharyngitis and cervical adenitis; PR, partial response. 
patients (partial or complete remission rate ranging from $40 \%$ to $67 \%$ ). Of note, as previously reported in adult PFAPA, tonsillectomy and/or adenoidectomy was inefficient in the majority. ${ }^{5}$ Although the size of the cohort was insufficient to perform statistical tests, it seems that regardless of the set of PFAPA criteria used, the disease course and therapeutic response were identical in the four criteria set groups. As a result, recent attempts to diagnose PFAPA more accurately may not translate into the identification of distinct patient profiles in terms of disease course and therapeutic management. Moreover, the recently described heterogeneous group of undefined systemic autoinflammatory diseases (USAID), defined as recurrent inflammation not corresponding to the clinical picture of any well-defined SAID or without pathogenic mutation causing a known hereditary SAID, seems to display similar characteristics. ${ }^{6}$ Therefore, the relevance of positioning PFAPA as a distinct entity than USAID in adult patients with non-monogenic periodic fevers is questionable.

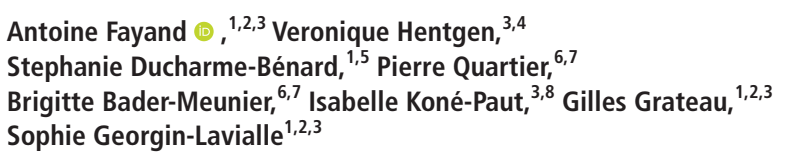

${ }^{1}$ Service de médecine interne, Hôpital Tenon, Assistance Publique-Hôpitaux de Paris, Paris, France

${ }_{2}^{2}$ Sorbonne Universite, Paris, Île-de-France, France

${ }^{3}$ French National Reference Center for Autoinflammatory Diseases (CEREMAIA), Le Kremlin-Bicêtre, France

${ }^{4}$ Service de pédiatrie, Centre hospitalier de Versailles, Le Chesnay, France

${ }^{5}$ Service de Médecine interne, Hôpital du Sacré-Coeur de Montréal, Montreal, Quebec, Canada

${ }^{6}$ Unité d'Immuno-Hématologie et Rhumatologie pédiatriques, Hopital universitaire Necker-Enfants malades, Assistance Publique-Hôpitaux de Paris, Paris, Île-de-France, France

${ }^{7}$ French National Reference Center for Rare Pediatric Inflammatory Rheumatic diseases and Systemic Autoimmune and Inflammatory Diseases (RAISE), Paris, France ${ }^{8}$ Service de Rhumatologie Pédiatrique, Hôpital Bicêtre, Assistance Publique-Hôpitaux de Paris, Le Kremlin-Bicêtre, France

Correspondence to Dr Antoine Fayand, Internal Medicine Department, Hôpital Tenon, Paris 75020, France; afayand@gmail.com

Contributors FA designed the study, collected clinical data and wrote the paper. HV designed the study, provided clinical data and critically revised the paper. D-BS critically revised the paper and reviewed English syntax. QP provided clinical data and critically revised the paper. B-MB provided clinical data and critically revised the paper. K-PI provided clinical data and critically revised the paper. GG provided clinical data and critically revised the paper. G-LS designed the study, provided clinical data and critically revised the paper.

Funding The authors have not declared a specific grant for this research from any funding agency in the public, commercial or not-for-profit sectors.

Competing interests All authors have nothing to disclose

Patient consent for publication Not required.

Provenance and peer review Not commissioned; internally peer reviewed.

(c) Author(s) (or their employer(s)) 2019. No commercial re-use. See rights and permissions. Published by BMJ.

- Additional material is published online only. To view please visit the journal online (http://dx.doi.org/10.1136/annrheumdis-2019-216827).

\section{A) Check for updates}

To cite Fayand A, Hentgen V, Ducharme-Bénard S, et al. Ann Rheum Dis Epub ahead of print: [please include Day Month Year]. doi:10.1136/annrheumdis-2019-216827

Received 15 December 2019

Accepted 18 December 2019

Ann Rheum Dis 2019;0:1-2. doi:10.1136/annrheumdis-2019-216827

\section{ORCID iD}

Antoine Fayand http://orcid.org/0000-0003-2720-4970

\section{REFERENCES}

1 Gattorno M, Hofer M, Federici S, et al. Classification criteria for autoinflammatory recurrent fevers. Ann Rheum Dis 2019;78:1025-32.

2 Cantarini L, Vitale A, Sicignano LL, et al. Diagnostic criteria for adult-onset periodic fever, aphthous stomatitis, pharyngitis, and cervical adenitis (PFAPA) syndrome. Front Immunol 2017;8:1018.

3 Vanoni F, Caorsi R, Aeby S, et al. Towards a new set of classification criteria for PFAPA syndrome. Pediatr Rheumatol Online J 2018;16:60.

4 Thomas KT, Feder HM, Lawton AR, et al. Periodic fever syndrome in children. J Pediatr 1999;135:15-21.

5 Cattalini M, Soliani M, Rigante D, et al. Basic characteristics of adults with periodic fever, aphthous stomatitis, pharyngitis, and adenopathy syndrome in comparison with the typical pediatric expression of disease. Mediators Inflamm 2015;2015:1-11.

6 Ter Haar NM, Eijkelboom C, Cantarini L, et al. Clinical characteristics and genetic analyses of 187 patients with undefined autoinflammatory diseases. Ann Rheum Dis 2019;78:1405-11. 